\title{
Comparison of Indonesian Throughflow transport observations, Makassar Strait to eastern Indian Ocean
}

\author{
Kevin Vranes ${ }^{1}$ and Arnold L. Gordon ${ }^{2}$ \\ Received 3 December 2004; revised 11 April 2005; accepted 14 April 2005; published 18 May 2005.
}

[1] The Pacific to Indian Ocean transport within the passageways of the Indonesian seas (ITF) varies on interannual and longer time scales associated with ENSO, the Asian monsoons and interannual climate variability of the Indian Ocean. Although direct current measurements of the ITF are of limited duration, none long enough to properly describe greater than annual variability of the ITF, observations indicate that the bulk of the ITF passes through Makassar Strait. The repeat expendable bathythermograph (XBT) IX1 section begun in 1983 provides the longest time series of the full ITF introduced into the Indian Ocean between northwest Australia and Java. We find that the surface to 600 dbar Makassar Strait transport, as measured by current meter moorings from December 1996 to July 1998 , correlates at $\mathrm{r}=0.77 \pm 0.14$ with the geostrophic transport constructed from IX1 XBT data for that time interval, with a 98 day lag. Citation: Vranes, K., and A. L. Gordon (2005), Comparison of Indonesian Throughflow transport observations, Makassar Strait to eastern Indian Ocean, Geophys. Res. Lett., 32, L10606, doi:10.1029/2004GL022158.

\section{Introduction}

[2] The multiple pathways within the Indonesian seas provide the only tropical link between ocean basins, allowing roughly $10 \mathrm{~Sv}\left(1 \mathrm{~Sv} \equiv 10^{6} \mathrm{~m}^{3} \mathrm{~s}^{-1}\right)$ of Pacific Ocean water to flow into the Indian Ocean [Gordon, 2001]. A relationship of the Indonesian Throughflow (ITF) to such climate features as ENSO and the Asian monsoon have been suggested [Godfrey, 1996]. In order to investigate such a relationship, a time series of ITF transport spanning many years, and perhaps decades, is needed. However, direct observations of the ITF are available for select passages and only for specific periods of time ranging from a few months to less than 2 years. The irregularity of ITF observations leads to an imperfect glimpse of its characteristics.

[3] While long-term volume transport time series of the ITF are nonexistent, temperature data from expendable bathythermographs (XBT) are fairly extensive throughout the region, although scattered unevenly in time and space. Of particular interest is the IX1 repeat XBT line, running since 1983 and sampled at better than biweekly since 1989 (Figure 1) [Meyers et al., 1995]. IX1 spans the westward flowing South Equatorial Current, which "contains" the \footnotetext{
USA.

${ }^{1}$ Department of Geology, University of Montana, Missoula, Montana,

${ }^{2}$ Lamont-Doherty Earth Observatory, Columbia University, Palisades, New York, USA.
}

Copyright 2005 by the American Geophysical Union. 0094-8276/05/2004GL022158\$05.00
ITF transport, between Java and northwest Australia. Using IX1, Meyers [1996], Sprintall et al. [2002], and Wijffels et al. [2002] have analyzed zonal geostrophic transport across the line, finding a mixture of seasonal, annual, interannual and eddy variability. Although it has been inferred that the net geostrophic transport calculated across IX1 is representative of the ITF, uncertainty in the calculations may be too large to faithfully monitor ITF variability.

[4] This study compares the directly-measured transport of the ITF fraction flowing through Makassar Strait from late November 1996 through mid-July 1998, with the estimated geostrophic transport across IX1 during the coincident period. The Makassar Strait throughflow represents the bulk of the ITF within the interior Indonesian seas [Gordon et al., 2003a]. Continuity of mass demands that Makassar flow either return to the Pacific east of Sulawesi through the Banda Sea, or else flow into the Indian Ocean somewhere through the IX1 line (the bathymetry between northern Australia and New Guinea in the Arafura Sea is too shallow to allow for any eastward transport there).

[5] A high level of correlation of the Makassar and the IX1 transports would help to determine whether the Makassar transport signal can be seen in IX1 and at what time scale. It would also provide confidence that techniques used to fill missing upper water column data in Makassar moorings [Vranes et al., 2002; Susanto and Gordon, 2005] are valid, and that the repeat XBT approach might be an effective long-term monitoring tool of the ITF.

\section{Data}

\subsection{Makassar Mooring Data}

[6] From late November 1996 to early July 1998, a 1.7-year record of current speed and temperature was obtained by two mooring arrays (MAK-1 at $2^{\circ} 52^{\prime} \mathrm{S}$, $118^{\circ} 27^{\prime} \mathrm{E}$ and MAK-2 at $2^{\circ} 51^{\prime} \mathrm{S}, 118^{\circ} 38^{\prime} \mathrm{E}$ ) in the Indonesian seas [Gordon et al., 1999]. The moorings were deployed in the Labani Channel, a $45 \mathrm{~km}$-wide constriction of the Makassar Strait (Figure 1). From T/S characteristics and transient tracers, Gordon and Fine [1996] and Ilahude and Gordon [1996] had previously shown that a large majority of all thermocline water transiting the Indonesian seas from the Pacific Ocean passes through the Makassar Strait. It was therefore assumed that detailed temporalvertical sampling of the Labani Channel would accurately describe most of the ITF thermocline flow.

[7] On MAK-1 current flow was measured from $200 \mathrm{~m}$ (at zero wire angle) to $1500 \mathrm{~m}$ depth at $20 \mathrm{~min} / \mathrm{sample}$. MAK-2 measured current speeds in the upper 150 meters over a three month period before failure of an upwardlooking acoustic Doppler current profiler (ADCP). Analysis of the Makassar data has attempted to characterize full- 


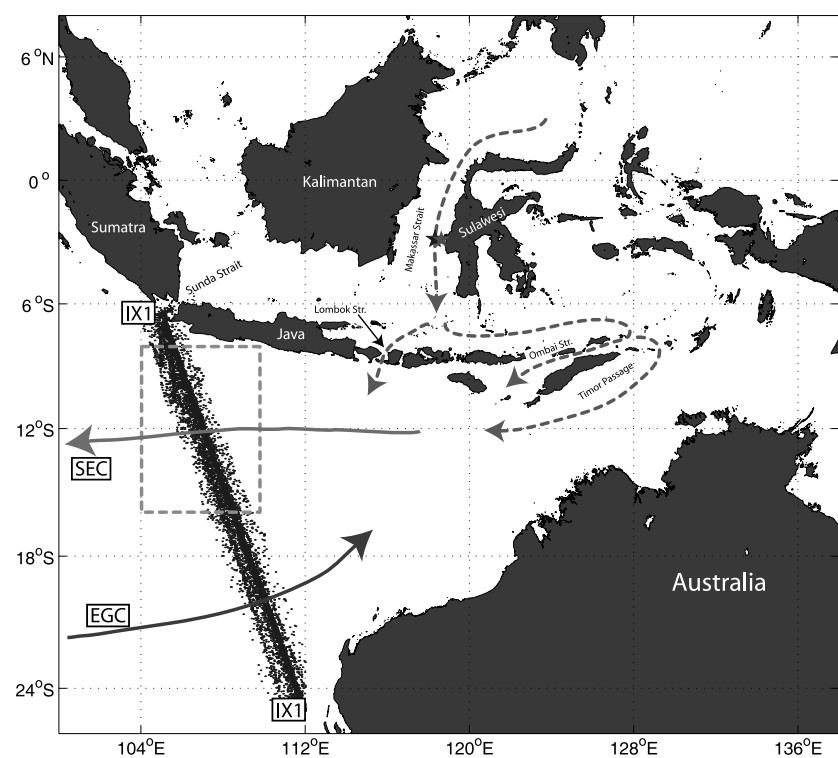

Figure 1. Makassar moorings (stars) and XBT/CTD casts along IX1 in Indonesian seas. Dashed arrows show main thermocline transport path through the interior seas. Solid arrows show approximate average position of Eastern Gyral Current (EGC) and approximate path of ITF exit flow into Indian Ocean South Equatorial Current (SEC). See color version of this figure in the HTML.

column volume and heat transports by employing various interpolative and extrapolative profiles to compensate for lack of current speed data above 200 dbar [Gordon et al., 1999; Vranes et al., 2002]. This study uses MAK-1 Profile D (MAK-1D) from Vranes et al. [2002], which is a seasonal mixture of three extrapolative profiles, informed by the limited ADCP data on MAK-2. The justification for this scheme is detailed by Vranes et al. [2002].

[8] Recently, Susanto and Gordon [2005] have constructed a synthetic 1.7-year record of Makassar flow (MAK-1/2 SB) by combining all available data from MAK-1 and MAK-2, including a recovered seven-month ADCP record from MAK-1 and the three-month MAK-2 ADCP record. To reconstruct upper layer flows (above the $200 \mathrm{~m}$ instrument) for periods without ADCP measurement, they fill missing ADCP data by extrapolating the surface layer current speed relationship to surface winds derived while the ADCP was functioning (a relationship revealed by Gordon et al. [2003b]). This study uses both MAK-1D from Vranes et al. [2002] and the reconstructed dataset by Susanto and Gordon [2005]. The 0-600 dbar volume transports of both sets correlate to $r=0.89$ at the $99 \%$ confidence level, while the $0-400$ dbar transports correlate to $\mathrm{r}=0.79$ at $99 \%$.

\subsection{Temperature Data Between Australia and Java}

[9] Temperature records in the Indonesian seas from $104^{\circ} \mathrm{E}-125^{\circ} \mathrm{E}$ to $6^{\circ} \mathrm{S}-25^{\circ} \mathrm{S}$ (Figure 1) are assembled from all available expendable bathythermograph (XBT) and conductivity-temperature-depth (CTD) casts. Most of the available data in this region comes from the well-sampled IX1 repeat XBT line, which has been running between Shark Bay, Australia and the Sunda Strait between Sumatra and Java since 1982, with the line sampled at better than biweekly by 1989 [Meyers et al., 1995; Meyers, 1996]. Most of the XBT data used is reliable only to 700 dbar.

[10] Following Meyers [1996], the 0-400 dbar (400 dbar reference level) geostrophic transport across $8.5^{\circ} \mathrm{S}$ to $15^{\circ} \mathrm{S}$ (dashed box in Figure 1) is calculated, substituting monthly average salinities from Conkright et al. [1998] for the annual salinity approximations used by Meyers [1996]. Geostrophic calculations are also made to 600 dbar (600 dbar reference level), matching the approximate depth of the controlling sill in the Makassar Strait.

[11] In order to compare IX1 transports to the 1.7-year Makassar mooring array, raw XBT data along IX1 was processed to achieve biweekly temporal spacing. Averaging is made over larger spatial windows and smaller time windows than that used by Meyers et al. [1995], replacing two-week averaging for overlapping bimonthly spacing and replacing $1^{\circ}$ (in latitude) boxes with $2^{\circ}$ boxes. Each individual cast in each box is assumed to represent the average for the box.

[12] Sprintall et al. [2002] updated the work by Meyers [1996], using data from two JADE and three WOCE cruises between 1989 - 1995 to complement the longer IX1 line, which lacks concurrent salinity information. Sprintall et al. [2002] found that eddies have a significant impact on the velocity structure across the line, influencing salinity as well as temperature. However, they also found that using historical salinity climatologies to stand in for concurrent salinity/ temperature information likely only affects transport calculations in deeper layers. Transports in the upper $400 \mathrm{db}$ calculated using salinity climatologies are likely to be as good as those using synoptic salinity records. In addition, we find that over $70 \%$ of the $0-600$ dbar variance in flow
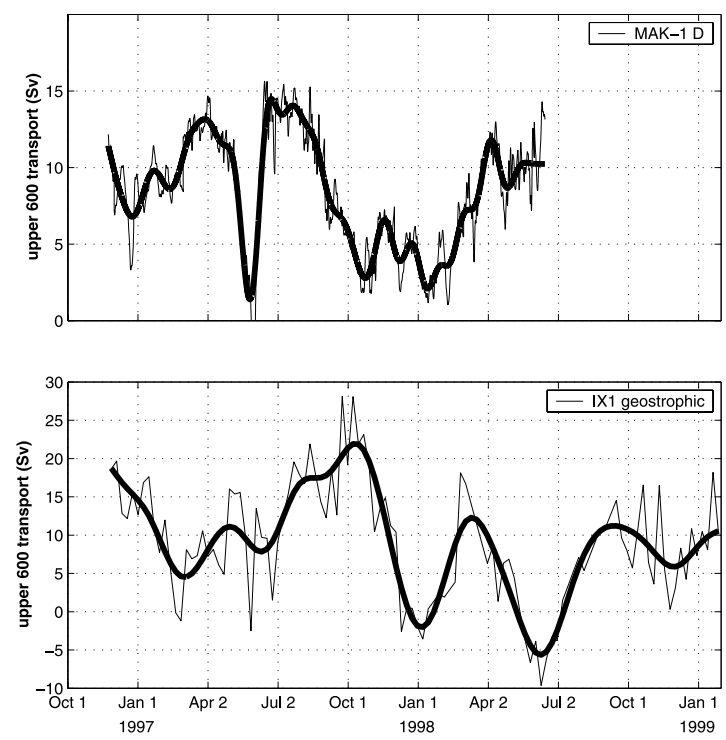

Figure 2. Top: MAK-1D 0-600 dbar volume transport time series with low pass filter applied (positive is southward transport). Bottom: geostrophic 0-600 dbar transport across IX1 (positive is westward transport). Note nearly simultaneous drop in ITF flow in both series in Spring 1997 (less apparent in IX1 series), which marks the passage of a coastal Kelvin wave, as described by Sprintall et al. [2000]. 

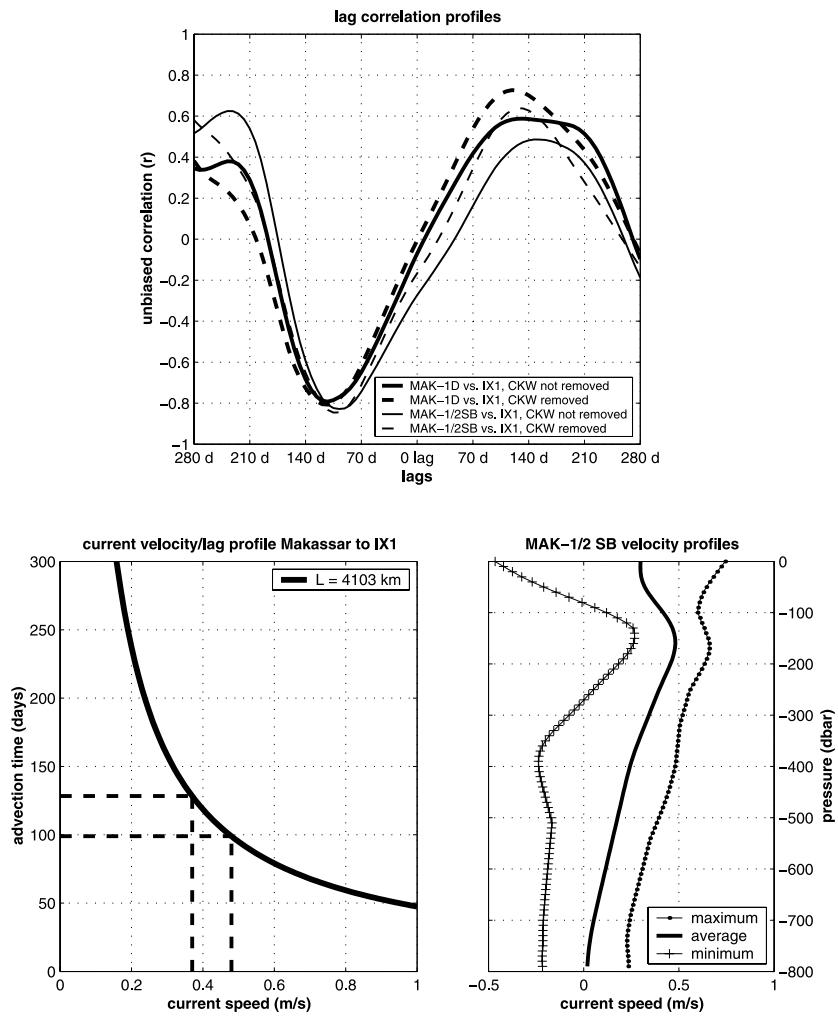

Figure 3. Top: Lag correlations between Makassar series and IX1 series. Thin lines represent low-pass filtered MAK-1/2 SB vs. filtered IX1 (dashed line is with coastal Kelvin wave event removed), thick lines represent MAK-1 $\mathrm{D}$ vs. IX1. Bottom left: relationship of time to distance between Labani Channel and $12^{\circ} \mathrm{S}$ at IX1 line. Bottom right: vertical velocity profiles ( $\max$, min and average) for MAK-1/2 SB.

across IX 1 is contained in the $0-200$ dbar layer, while only $6 \%$ of the variance is contained below $400 \mathrm{dbar}$.

\section{Comparison of MAK-1 to IX1}

[13] Upper 600 dbar transport of MAK-1D and the derived IX1 $0-600$ dbar geostrophic transport during the 1.7-year duration of MAK-1 are shown in Figure 2. MAK-1/2 SB is not shown as it closely matches MAK-1D. The long-period behavior of the Makassar series and IX1 are well matched with some apparent lag. A large current reversal is nearly simultaneous in both series in late May 1997, with the event first expressed in IX1. This event is likely the result of a strong coastal Kelvin wave (CKW) originating along the Indian Ocean equator, propagating along the Lesser Sunda island chain and entering the Makassar Strait through the Lombok Channel [Sprintall et al., 2000; Vranes, 2003].

[14] A variety of lag correlations (Figure 3) are computed between various permutations of the IX1 vs. MAK-1D and IX1 vs. MAK-1/2SB series with two-week spacing, correlating the original series, smoothed series to remove high frequency energy, and correlating after removing the CKW event from both series. Error in the correlation calculation is estimated through a bootstrap method [Emery and Thomson, 1997], adding random noise of amplitude equal to one standard deviation to the original raw MAK and IX1 volume transport time series before averaging and correlating. The error interval cited is the $95 \%$ confidence level derived by bootstrap.

[15] Maximum correlations between IX1 and MAK series are found at approximately 98 days, whether the CKW is retained or removed before correlating. However, removing the $\mathrm{CKW}$ and smoothing the series raises maximum (unbiased) correlation by 0.16 to $\mathrm{r}=0.77 \pm 0.14$, indicating that MAK-1D and IX1 are matched well at low frequencies, while less well-matched at higher frequencies. The correlation increases to $\mathrm{r}=0.81 \pm 0.12$ when the $0-400 \mathrm{dbar}$ transports are compared. The MAK-1/2 SB series correlates at $\mathrm{r}=0.66 \pm 0.16$ with IX1 $(0-600 \mathrm{dbar})$.

[16] Westward 0-600 dbar volume transport through IX1 is lagged by 98 days and smoothed, then overlain by smoothed MAK-1D and MAK-1/2 SB transport in Figure 4. Assuming an advective length scale of $\mathrm{L}=4100 \mathrm{~km}$ between the Makassar mooring location at $3^{\circ} \mathrm{S} / 118^{\circ} \mathrm{E}$ and the IX1 line at $11^{\circ} \mathrm{S} / 106^{\circ} \mathrm{E}$, a lag of 98 days requires an average $0-$ $600 \mathrm{dbar}$ advective speed of close to $\mathrm{V}=0.5 \mathrm{~m} / \mathrm{s}$. This length scale assumes no flow through Lombok Strait and follows the generally accepted Makassar throughflow path around East Timor and through Timor Strait before reaching IX1 [Gordon and Fine, 1996; Gordon, 2001; Hautala et al., 2001] and thus is the maximum advective length scale for the Makassar IX1 path. The average 0-400 dbar MAK-1/2 SB current speed and maximum average speed for any level between 0 $400 \mathrm{dbar}$ are $0.37 \mathrm{~m} / \mathrm{s}(0.3$ over $0-600 \mathrm{dbar})$ and $0.7 \mathrm{~m} / \mathrm{s}$ respectively (Figure 3, bottom right panel). MAK-1/2 SB,
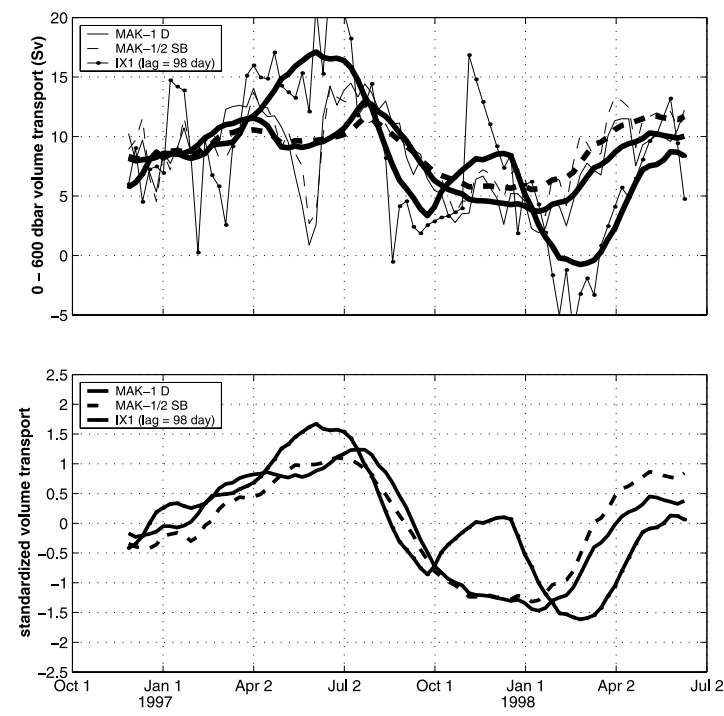

Figure 4. Top panel: $0-600$ dbar volume transport through MAK-1 D, MAK-1/2 SB and IX1 (lagged 98 days). Thin lines are two-week running means for MAK data, raw data for IX1; thick lines are 6-week running means for all series. Bottom panel: MAK-1 D, MAK-1/2 SB and lagged IX1 series with Spring 1997 Kelvin wave event removed, standardized (mean subtracted and result divided by standard deviation) to show match in variability between the series without differences in amplitude swamping variability. See color version of this figure in the HTML. 
utilizing ADCP data for upper level flows rather than extrapolating to constant values, shows slightly higher upper level average current speeds than MAK-1 D, with maximum speeds exceeding that needed to fit within the observed lag. For average $0-400 \mathrm{dbar}$ flow of $\mathrm{V}=0.37 \mathrm{~m} / \mathrm{s}$, the maximum lag should increase to roughly 125 days. Shortening the length scale (by adding flow through Lombok, for instance) decreases the difference between observed current speeds and the higher speeds required to produce the observed lag.

[17] Propagation speed of the CKW, transiting from IX1 to Makassar in two weeks, is much faster than typical advection speed through the Makassar Strait, thus explaining the higher lag correlations with CKW removal.

\section{Discussion and Conclusion}

[18] One purpose of matching Makassar flow to IX1 is to examine whether the 20-year IX1 record might be an appropriate proxy for interior Indonesian seas flow. Another is to confirm the feasibility of the Vranes et al. [2002] extrapolation profiles to fill missing upper level Makassar data. The maximum (unbiased) correlation between MAK-1D series and IX1 during the December 1996-July 1998 duration of MAK- 1 is $r=0.77 \pm 0.14$, which rises when only the $0-400$ dbar flows are compared. Correlations are smaller with other MAK-1 extrapolation profiles as well as with the MAK-1/2 SB series, indicating that the imposition of a seasonal cycle inherent to the MAK-1D series may drive the correlation higher.

[19] Correlations increase considerably with time series smoothing to remove high frequency energies, indicating that a reconstruction of Makassar flows using IX1 is valid for long-period behaviors, but not for higher frequency activity. This is to be expected as there are likely to be transient eddies across the IX1 line [Sprintall et al., 2002] that do not affect the Makassar throughflow, and local effects in the Makassar Strait not present in IX1 (for example, those described by Gordon et al. [2003b]). We also note that the amplitude of variability is much greater in the IX1 series than the Makassar series (Figures 2 and 4). This could be due to seasonal storage in the surface layers and thermoclines of interior seas along the advection path between Makassar Strait and IX1. For instance, Gordon and Susanto [2001] find up to $4 \mathrm{~Sv}$ of Banda Sea divergence, modulated strongly during the El Niño period of 1997, and Potemra et al. [2003] find an annual cycle of $6 \mathrm{~Sv}$ convergence (from $-2 \mathrm{~Sv}$ to $4 \mathrm{~Sv}$ ) in the Savu Sea. Since all advective flow (10 Sv annual average) is never instantaneously captured by interior seas, that is, some flow continues through the interior seas even while a fraction is stored, variability in flow between Makassar and IX1 can remain in phase at some lag even while the amplitude of flow is not matched. The presence of regular semiannual transient Kelvin waves and Rossby waves described by Clarke and Liu [1994], Vranes [2003], and Wijffels and Meyers [2004] will distort any reconstruction in time space, as the transient waves affect both IX1 and the Makassar Strait in sequence, but much more quickly than the 98-day advective time scale. Vranes [2003] showed from TOPEX/Poseidon sea surface height anomaly (SSHa) data that the transient coastal Kelvin waves can be expected in most years. The TOPEX SSHa data is unreliable in the interior Indonesian seas, and thus coastal Kelvin waves that might affect the Makassar Strait can only be reliably tracked to the southern edge of the Lombok Strait. But Vranes [2003] shows that the Spring 1997 CKW was a particularly large event, with a larger sea surface height anomaly (SSHa) expression along its equatorial and coastal waveguide than any other eastwardpropagating wave during the 9-year duration of the TOPEX/Poseidon satellite.

[20] The Makassar flow data used in this study was of only 1.7-year duration. While its close match to flow across IX1 suggests that IX1 might be an accurate proxy for interior Indonesian flow, at least in the upper $600 \mathrm{dbar}$, the record is much too short to say this with certainty on interannual time scales.

[21] Acknowledgments. This work was supported by National Science Foundation grant number OCE 02-19782. Dwi Susanto is gratefully acknowledged for providing the MAK-1/2 SB grid. Lamont-Doherty contribution 6758 .

\section{References}

Clarke, A. J., and X. Liu (1994), Interannual sea level in the northern and eastern Indian Ocean, J. Phys. Oceanogr., 24, 1224-1235.

Conkright, M. E., S. Levitus, T. O’Brien, T. P. Boyer, J. I. Antonov, and C. Stephens (1998), World Ocean Atlas 1998 [CD-ROM], NOAA, Silver Spring, Md.

Emery, W. J., and R. E. Thomson (1997), Data Analysis Methods in Physical Oceanography, 634 pp., Elsevier, New York.

Godfrey, J. S. (1996), The effect of the Indonesian Throughflow on ocean circulation and heat exchange with the atmosphere: A review, J. Geophys. Res., 101(C5), 12,217-12,238.

Gordon, A. L. (2001), Interocean exchange, in Ocean Circulation and Climate: Observing and Modeling the Global Ocean, Int. Geophys. Ser, vol. 77, edited by G. Siedler, J. Church, and J. Gould, pp. 303314, Elsevier, New York.

Gordon, A. L., and R. A. Fine (1996), Pathways of water between the Pacific and Indian Oceans in the Indonesian seas, Nature, 379, 146-149. Gordon, A. L., and R. D. Susanto (2001), Banda Sea surface-layer divergence, Ocean Dyn., 52, 2-10.

Gordon, A. L., R. D. Susanto, and A. Ffield (1999), Throughflow within Makassar Strait, Geophys. Res. Lett., 26(21), 3325-3328.

Gordon, A. L., C. Giulivi, and A. G. Ilahude (2003a), Deep topographic barriers within the Indonesian seas, Deep Sea Res., Part II, 50(12-13), 2205-2228.

Gordon, A. L., R. D. Susanto, and K. Vranes (2003b), Cool Indonesian Throughflow is a consequence of restricted surface layer flow, Nature, $425,824-828$.

Hautala, S., J. Sprintall, J. T. Potemra, J. C. Chong, W. Pandoe, N. A. Bray, and A. G. Ilahude (2001), Velocity structure and transport of the Indonesian Throughflow in the major straits restricting flow into the Indian Ocean, J. Geophys. Res., 106(C9), 19,527-19,546.

Ilahude, A. G., and A. L. Gordon (1996), Thermocline stratification within the Indonesian seas, J. Geophys. Res., 101(C5), 12,401-12,409.

Meyers, G. (1996), Variation of Indonesian Throughflow and the El NiñoSouthern Oscillation, J. Geophys. Res., 101(C5), 12,255-12,263.

Meyers, G., R. J. Bailey, and A. P. Worby (1995), Geostrophic transport of Indonesian Throughflow, Deep Sea Res., 42(7), 1163-1174.

Potemra, J. T., J. Sprintall, S. L. Hautala, and W. Pandoe (2003), Observed estimates of convergence in the Savu Sea, Indonesia, J. Geophys. Res., 108(C1), 3001, doi:10.1029/2002JC001507.

Sprintall, J., A. L. Gordon, R. Murtugudde, and R. D. Susanto (2000), A semiannual Indian Ocean forced Kelvin wave observed in the Indonesian seas in May 1997, J. Geophys. Res., 105(C7), 17,217-17,230.

Sprintall, J., S. Wijffels, T. Chereskin, and N. A. Bray (2002), The JADE and WOCE I10/IR6 throughflow sections in the southeast Indian Ocean. Part 2: Velocity and transports, Deep Sea Res., Part II, 49(7-8), $1363-$ 1389.

Susanto, R. D., and A. L. Gordon (2005), Velocity and transport of the Makassar Strait throughflow, J. Geophys. Res., 110, C01005, doi:10.1029/2004JC002425.

Vranes, K. (2003), The intraseasonal to interannual variability of the Indonesian Throughflow, Ph.D. thesis, 174 pp., Columbia Univ., New York. 
Vranes, K., A. L. Gordon, and A. Ffield (2002), The heat transport of the Indonesian Throughflow and implications for the Indian Ocean heat budget, Deep Sea Res., Part II, 49(7-8), 1391-1410.

Wijffels, S., and G. Meyers (2004), An intersection of oceanic waveguides: Variability in the Indonesian Throughflow region, J. Phys. Oceanogr. $34(5), 1232-1253$

Wijffels, S., J. Sprintall, M. Fieux, and N. A. Bray (2002), The JADE and WOCE I10/IR6 throughflow sections in the southeast Indian Ocean.
Part I: Water mass distribution and variability, Deep Sea Res., Part II, $49(7-8), 1341-1362$

A. L. Gordon, Lamont-Doherty Earth Observatory, Columbia University, Palisades, NY 19064, USA.

K. Vranes, Department of Geology, University of Montana, Missoula, MT 59812, USA. (kevin.vranes@umontana.edu) 